\title{
Relação teoria-prática no ensino de educação nutricional ${ }^{1}$
}

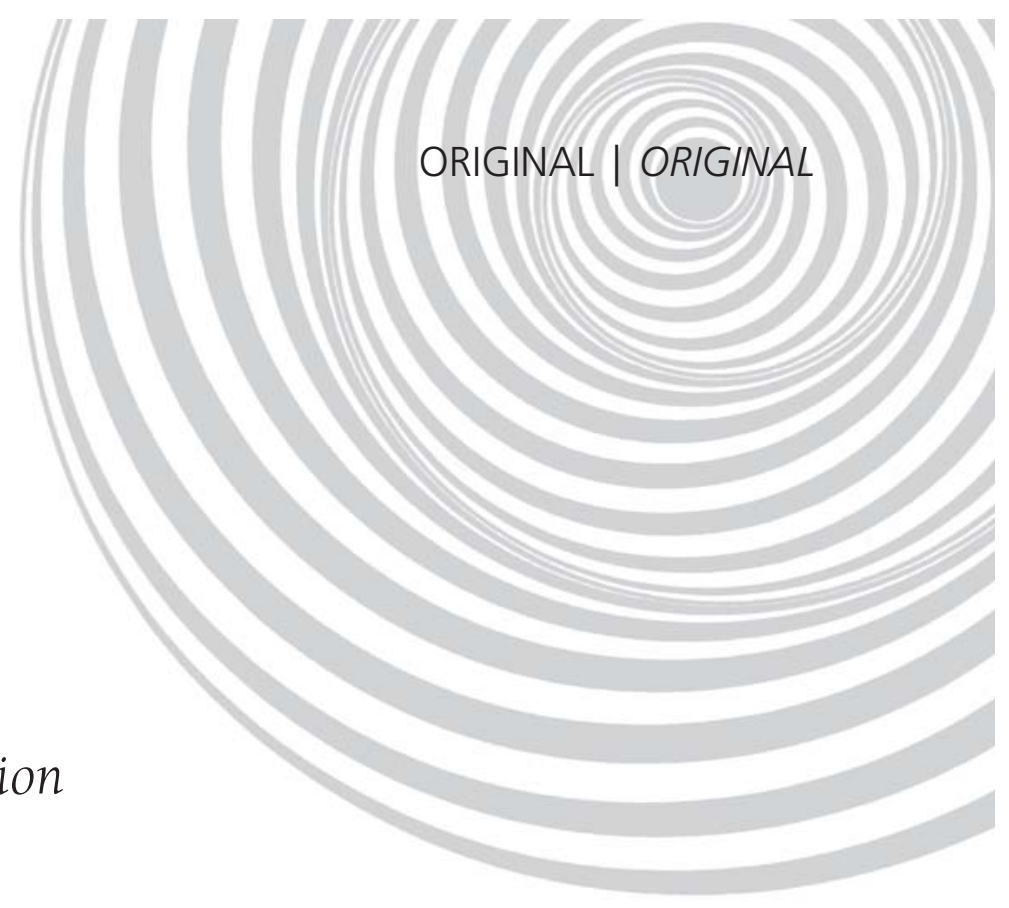

\section{Theory-practice relationship in nutrition education teaching}

Ana Carolina FRANCO²

Maria Cristina Faber BOOG $^{3}$

RE S U M O

\section{Objetivo}

Apresentar e analisar criticamente as diversas concepções que professores da disciplina educação nutricional têm de atividade prática e como entendem a relação teoria-prática.

\section{Métodos}

O estudo foi desenvolvido nas Instituições de Ensino Superior do Estado de São Paulo, Brasil, que apresentaram reconhecimento pelo Ministério da Educação até o ano de 1999. A partir dessa informação foram realizadas entrevistas com os docentes da disciplina Educação Nutricional de cada uma dessas Instituições, totalizando 11 sujeitos. Os resultados foram analisados qualitativamente, na perspectiva da hermenêutica-dialética, considerada como um caminho do pensamento.

\section{Resultados}

As docentes apresentaram pensamentos similares em relação à importância da prática, porém concepções variadas de atividade prática em educação nutricional. Algumas consideram que atividades práticas são suficientes para a formação do aluno e não buscam fundamentação teórica em ciências humanas e sociais. Observou-se ainda hipervalorização da prática em detrimento da teoria. Esses aspectos contribuem para comprometer a efetivação da relação teoria-prática.

\section{Conclusão}

Cabe aos cursos de graduação e aos órgãos fiscalizadores do ensino, a discussão a respeito da formação dos docentes, da concepção de atividade prática e de formas mais eficazes para que se efetive o movimento dialético da prática com a teoria. É necessário estimular, desde o início da graduação, a articulação entre teoria e prática, a fim de possibilitar aos alunos a contextualização na construção de conhecimentos e formação de compromissos sociais e éticos.

Termos de indexação: docentes; educação alimentar e nutricional; ensino superior; nutricionista.

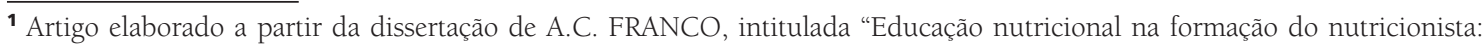
bases teóricas e relação teoria-prática". Programa de Mestrado em Enfermagem, Universidade Estadual de Campinas; 2006. Apoio: Coordenação de Aperfeiçoamento de Pessoal de Nível Superior, processo 5603/2004.

${ }^{2}$ Faculdade de Medicina de Itajubá, Curso de Nutrição. R. Renó Júnior, 368, Bairro São Vicente, 37502-138, Itajubá, MG, Brasil.

${ }^{3}$ Universidade Estadual de Campinas, Faculdade de Ciências Médicas, Departamento de Enfermagem. Campinas, SP, Brasil. 
644 A.C. FRANCO \& M.C.F. BOOG

\section{A B S TR A C T}

\section{Objective}

The objective of this paper is to critically identify and analyze the many concepts that professors of the subject nutrition education have of practice and how they understand the theory-practice relationship.

\section{Methods}

The study was done in universities and colleges of the State of São Paulo, Brazil, that have been registered at the Ministry of Education since 1999. With this information, professors of the subject nutrition education were interviewed in all these institutions totaling 11 individuals. The results were analyzed qualitatively, using the hermeneutic-dialectic method.

\section{Results}

The professors had similar opinions regarding the importance of practice; however what practice meant in nutrition education varied. Some consider that practical activities are enough for the formation of the student and do not search theoretical fundamentals in social and human sciences. We also observed that practice was overvalued in relation to theory. All these aspects contribute to compromise the effectiveness of the theory-practice relationship.

\section{Conclusion}

It is up to the graduation courses and the government departments that surveil education to discuss the education of the professors, the concepts behind practical activities and more effective ways to work the dialectics between practice and theory. It is necessary to stimulate, from the beginning of the graduation course, the articulation between theory and practice in order to allow the students to contextualize the acquisition of knowledge and form social and ethical compromises.

Indexing terms: faculty; food and nutrition education; education, higher; nutritionist.

\section{N T R O D U ÇÃ O}

A disciplina educação nutricional apresenta um diferencial em relação às demais disciplinas do curso de nutrição, por exigir do docente o ensino de conhecimentos diferentes daqueles que compõem o instrumental técnico de nutrição, pois desafia professores e alunos a se relacionar com contextos, pessoas, realidades e uma relação teoria-prática, em que o conhecimento técnico se revela insuficiente para lidar com situações vivenciadas em campo.

As Diretrizes Curriculares do Curso de Graduação em Nutrição (DCNCN), instituídas pelo Conselho Nacional de Educação da Câmara de Educação Superior (Parecer n.5 de 7/11/2001), determinam que os conteúdos curriculares desse curso contemplem as ciências sociais e humanas, que são áreas de conhecimentos que abordam a educação. Além disso, as Diretizes estabelecem que o ensino deve ser crítico, reflexivo, criativo e que deve conter atividades teóricas e práticas desde o início, assegurando a definição de estratégias pedagógicas que articulem ensino/pesquisa/extensão-assistência'.

Em 1996, a Lei de Diretrizes e Bases da Educação Nacional (LDB), que instituiu, para as Universidades, autonomia na fixação dos currículos, dos cursos e programas, eliminou a exigência de cumprimento de um currículo mínimo. O parecer do Conselho Nacional de Educação e da Câmara de Educação Superior 67/2003 dispõe sobre essa liberdade, garantida aos cursos para adequar seu currículo de acordo com as demandas nacionais e regionais, o que possibilita grande variação da carga horária destinada às disciplinas². As implicações dessa lei podem ser constatadas em estudo realizado por Canesqui \& Garcia $^{3}$ sobre a presença e os conteúdos das disciplinas de ciências humanas e sociais em 12 cursos de nutrição. As disciplinas foram separadas por áreas de conhecimento, e a educação nutricional e a nutrição em saúde pública foram unidas em uma mesma categoria, para a qual reserva-se, em média, $4,70 \%$ da carga horária, variando entre 3,26\% e $6,06 \%$. Outra área de conhecimento estudada por 
essas autoras, que subsidia a disciplina educação nutricional, foi a de ciências humanas que, nesse caso, englobou as disciplinas sociologia, filosofia, antropologia, geografia e psicologia. A representação dessa área na carga horária total do curso foi em média $4,98 \%$ e oscilou entre $2,62 \%$ e $8,33 \%$.

Percebe-se a diferença de prioridade dada ao componente educação na formação do nutricionista, nos dias atuais, comparando os dados acima à proporção de carga horária definida para as "ciências pedagógicas" na graduação, a partir da I Conferência de Treinamento de Nutricionistas-dietistas, de 1966, quando a importância dessa área evidenciou-se por ser representada como constituinte da raiz do curso, ocupando 1/5 da sua base 4 .

Face aos desafios que a sociedade brasileira impõe atualmente à categoria dos nutricionistas, na medida em que a educação nutricional, voltada à promoção da alimentação saudável, constitui uma das diretrizes da Política de Alimentação e Nutrição (PNAN) $)^{5}$, cabe analisar as condições em que se dá a formação do nutricionista como educador, sendo que um dos aspectos que consolidam essa formação é a relação entre teoria e prática.

Para proceder à análise dessa questão buscou-se um referencial teórico que pudesse subsidiar a discussão acerca da preparação do aluno para ir à comunidade, se relacionar com pessoas de classes sociais e culturas diversas da sua, estabelecer vínculos, compreender a condição humana e a situação sócio-política condicionante e determinante do processo saúde-doença. Esse referencial foi encontrado em três autores do campo da educação: Edgar Morin, Paulo Freire e Franscisco Imbernón, cujos fundamentos serão discutidos e apresentados a seguir.

O conhecimento especializado é apontado por Morin ${ }^{6}$ como uma forma de abstração que impede a contextualização de problemas particulares, de modo que o conhecimento técnico fica reservado aos especialistas, cuja competência em uma área específica pode transformar-se em incompetência quando essa mesma área é modificada por algum acontecimento novo:
[...] Como nossa educação nos ensinou a separar, compartimentar, isolar e, não, a unir os conhecimentos, o conjunto deles constitui um quebra-cabeças ininteligível. [...]. A incapacidade de organizar o saber disperso e compartimentado conduz à atrofia da disposição mental natural de contextualizar e de globalizar ${ }^{6}$ (p.42).

Essa especialização do conhecimento contribui para a fragmentação dos saberes oriundos das diversas disciplinas do curso, assim como foi evidenciado em estudo sobre a percepção de pediatras e nutricionistas a respeito de sua formação. A dicotomia existente entre teoria e prática na graduação revelou-se um fator complicador do bom desempenho profissional, porque dificulta o entendimento do contexto no momento da prática7. Tal concepção reflete a "teoria desconexa" apontada por Achterberg ${ }^{8}$, segundo a qual os estudantes não conseguem estabelecer relação entre a teoria estudada e a situação prática no campo. Para essa autora, que vem estudando, especificamente, a educação nutricional, existem duas possibilidades de relação entre teoria e prática: a "experiência desconexa" e a "conexão teoria-prática". A primeira representa as lições que os alunos aprendem a partir de observações ou experiências práticas que, por não serem formalizadas, impossibilitam a explicitação desses achados nas teorias de educação, impedindo, igualmente, a reflexão do aluno. A segunda representa o intuito de estimular a relação entre pesquisa/teoria e prática, na qual ambas devem ser combinadas a fim de facilitar o ensino em educação nutricional. Nessa perspectiva, conclui-se que não se pode dar primazia à teoria ou à prática, mas sim, fazer com que ambas se tornem recíprocas e constituam uma totalidade, produzida em um contexto, para que, então, todo o potencial de ensino seja alcançado 9 .

A lacuna existente entre teoria e prática foi reafirmada por Dinucci et al. ${ }^{10}$ ao estudarem a representação social acerca do curso e da profissão, de egressos da Universidade Federal do Mato Grosso. Os autores relatam que o curso dessa 
Instituição está distante do currículo ideal, que propõe uma relação dialética entre teoria e prática, partindo da reflexão crítica sobre a segunda, condição na qual os alunos participariam ativamente na construção do conhecimento. A dicotomia teórico-prática da graduação e a fragmentação disciplinar dos currículos, também observada por Fagundes \& Burnham ${ }^{11}$, reflete-se na atuação dos professores, que acabam reconhecendo a tarefa educativa como transmissão teórica de conhecimentos, que impossibilita aos alunos a articulação dos novos saberes com as novas práticas.

Paulo Freire, ao propor uma concepção problematizadora de educação, na qual educador e educando vivenciam situações concretas da realidade, de forma a construir um conhecimento permeado pela reflexão sobre os aspectos éticos e sociais do seu agir técnico, critica o ensino caracterizado por um diálogo singular e vertical entre educador e educando ${ }^{12}$. Essa relação, na qual o educador narra conteúdos, fala da realidade como algo estático e alheio às experiências dos educandos, conduzindo à memorização mecânica do conteúdo, é considerada por ele "bancária", pois a única margem de ação aos educandos é a condição de receberem os "depósitos" vindos dos educadores. Nessa perspectiva, o educador é o sujeito ativo do processo enquanto os educandos são sujeitos passivos.

Freire propõe uma concepção de educação capaz de proporcionar aos educandos a possibilidade de se tornarem sujeitos ativos do processo que estão vivendo, participando de forma reflexiva e crítica da construção de conhecimentos, sempre dentro da realidade. Esse seria o ensino "problematizador", no qual se instrui o aluno a pensar e não, simplesmente, aceitar o conteúdo que lhe foi transferido. Tal concepção problematizadora exige a superação da contradição educador-educando, por intermédio do diálogo, que se torna condição básica para o conhecimento, para a interação, constituindo, portanto, a mediação do processo educativo. Esse ensino tem caráter reflexivo, e é libertador, pois, na medida em que os alunos percebem as razões das dificuldades em suas ações, alcançam a razão dos obstáculos reais. O ensino "problematizador" caminha no sentido contrário ao da alienação induzida pelo ensino "bancário", no qual, ingenuamente, o aluno pressupõe que, dominando a teoria, agirá de forma competente na prática ${ }^{13-16}$.

Enquanto, na concepção "bancária" [...] o educador vai "enchendo" os educandos de falso saber, que são os conteúdos impostos, na prática problematizadora, vão os educandos desenvolvendo o seu poder de captação e de compreensão do mundo que thes aparece, em suas relações com ele, não mais como uma realidade estática, mas como uma realidade em transformação, em processo ${ }^{15}$ (p.71).

O exercício de um trabalho reflexivo com o educando, exigindo que docentes e alunos compartilhem, efetivamente, do processo de construção do conhecimento ${ }^{17}$, também é proposto por Imbernón ${ }^{18}$, que ressalta a obsolescência da transmissão de conhecimentos no contexto atual, marcado por um incremento acelerado e por mudanças vertiginosas no conhecimento científico, na sociedade, nos meios de comunicação e no aparato tecnológico. Nesse caso, os professores não são apenas técnicos, mas participam ativa e criticamente nos processos de mudança social.

Um fator importante na capacitação profissional é a postura do professor frente ao planejamento de uma tarefa cuja responsabilidade é maior do que a mera transmissão de conteúdos, devendo se apresentar como facilitador da articulação entre a teoria e a situação prática, capaz de provocar a participação dos alunos. Quanto à relação dialética entre teoria e prática educativa nas Instituições, o mesmo autor ressalta que deve favorecer uma proposta pedagógica que conduza o aluno à realidade, permitindo a interpretação, a reinterpretação e a sistematização das experiências passadas e presentes, estimulando, portanto, a reflexão ${ }^{18}$.

Ao não articular teoria-prática a tendência ao empobrecimento teórico da formação, em nome de atividades práticas ocorrerá freqüen- 
temente, de modo que esta poderá suprimir a outra, desestimulando o enfrentamento das dificuldades de compreensão e aprendizagem dos alunos e professores ${ }^{19}$. Frente a isso, há necessidade de descontrução do paradigma dicotômico entre o saber e o fazer, para que, então, apontem-se novos caminhos e perspectivas para as mudanças esperadas na formação profissional ${ }^{20}$.

A relação entre teoria e prática, em educação nutricional, é uma relação entre teoria de nutrição e teoria de educação com prática de nutrição em campo. Seria ingênuo acreditar que a formação educativa se dá espontaneamente, mediante a execução em campo de práticas de nutrição, não atreladas a uma formação sólida em educação. Isso posto, a presente pesquisa teve como objetivo apresentar e analisar criticamente as diversas concepções que professores da disciplina educação nutricional têm de atividade prática e como entendem a relação teoria-prática.

\section{M É T O D O S}

A abordagem adotada para o presente trabalho foi qualitativa, uma vez que a intenção era compreender os significados atribuídos à relação teoria-prática. Essa abordagem busca entender os fenômenos de acordo com a perspectiva dos participantes e, para isso, utiliza entrevistas em profundidade, nas quais há o contato direto do pesquisador com os sujeitos de pesquisa ${ }^{21}$.

Os sujeitos foram os docentes da disciplina educação nutricional de cursos pertencentes a instituições selecionadas de acordo com o ano de autorização e reconhecimento pelo Ministério da Educação (MEC). Foram incluídas aquelas que o obtiveram até dezembro de 1999, pois, dessa forma, as instituições estudadas teriam, pelo menos, uma turma formada com o curso já reconhecido desde o início da graduação. No caso de apresentarem mais de um Campus oferecendo o curso de nutrição, escolheu-se aquele com maior tempo de funcionamento.
Esses dados foram colhidos a partir da página eletrônica do Instituto Nacional de Estudos e Pesquisas Educacionais Anísio Teixeira (INEP). Considerando todos estes aspectos, foram encontradas 12 Instituições, portanto, 12 participantes. No entanto, apenas 10 Instituições de Ensino Superior (IES) foram incluídas, porque no momento do estudo, em duas delas, a disciplina educação nutricional encontrava-se sem professor responsável.

Participaram, portanto, uma universidade pública e nove IES privadas, sendo quatro no município de São Paulo e seis no interior paulista. Apesar de o estudo abranger 10 IES, houve 11 entrevistas, pois em uma das universidades havia duas docentes responsáveis pela disciplina em questão.

Os coordenadores de curso das instituições foram avisados antecipadamente sobre o trabalho. Os sujeitos foram contatados por telefonema ou e-mail, para informá-los sobre o estudo e enfatizar a importância da sua participação. Após a aquiescência, agendou-se a data da entrevista.

Utilizou-se um roteiro de entrevista organizado na forma de tópicos, semi-estruturado, possibilitando a formulação de questões abertas. Essa técnica de entrevista proporciona boa interação entre pesquisador e sujeito pesquisado, assegurando ao entrevistador a coleta de uma ampla gama de informações ${ }^{22}$. A entrevista semi-estruturada proporciona a melhor qualidade de informações, dados mais fidedignos e a melhor utilização do tempo, quando comparada com outros quatro métodos de entrevista ${ }^{23}$.

A entrevista é utilizada para obtenção de informações sobre o que os sujeitos sabem, crêem, sentem, pretendem fazer, bem como acerca das suas explicações ou razões a respeito das opiniões precedentes. Além disso, apresenta as seguintes vantagens: possibilita a obtenção de dados referentes aos diversos aspectos do problema em estudo, é uma técnica eficiente para a obtenção de dados em profundidade acerca do comportamento humano e os dados obtidos são suscetíveis de categorização e, também, se pertinente, de quantificação ${ }^{24}$. 
As entrevistas foram realizadas pela própria pesquisadora entre 25 de fevereiro e 9 de maio de 2005, totalizando 74 dias, nas próprias IES, cujas distâncias variaram de 15 a $570 \mathrm{~km}$ da instituição responsável pela pesquisa. As entrevistas foram gravadas, permitindo assim a total apreensão dos depoimentos. O tempo médio de duração de cada entrevista foi de 40 minutos e a transcrição de cada uma delas durou, em média, quatro horas.

Para preservar o sigilo sobre a identidade dos participantes, optou-se por alterar os nomes das docentes para tipos de aromas: absinto, alfazema, almíscar, âmbar, bálsamo, benjoim, camomila, cânfora, jasmim, lavanda e mirra. O estudo atende às disposições da Resolução n. 196/96, referente a pesquisas envolvendo seres humanos, tendo sido submetido ao Comitê de Ética e aprovado com o parecer n.323/ 2004.

A discussão dos resultados da entrevista foi realizada à luz da hermenêutica-dialética, conceituada por Minayo ${ }^{22}$ como um caminho do pensamento, representando a interpretação da fala do sujeito dentro da sua realidade social.

A união da hermenêutica com a dialética leva a que o intérprete busque entender o texto, a fala, o depoimento como resultado de um processo social (trabalho e dominação) e processo de conhecimento (expresso em linguagem) ambos frutos de múltiplas determinações mas com significado especifico (grifo do autor) ${ }^{22}$ (p.227).

A hermenêutica é destinada ao texto que exige explicação ou compreensão, buscando os significados subentendidos e explicitando as contradições dentro dele ${ }^{22}$.

$\mathrm{Na}$ apresentação das falas foi mantida a sintaxe original do texto, por considerar que a expressão original revela com mais exatidão a forma de pensar e ser dos sujeitos.

Após as transcrições revelou-se acentuada recorrência de algumas palavras que remetiam aos pensamentos de Paulo Freire. Utilizou-se, então, de forma pontual, o recurso da análise temática do discurso, que leva em conta a freqüência dos temas extraídos do conjunto dos depoimentos. Essa recorrência de importância considera as repetições insistentes de um tema, que ressurgem em vários momentos, revelando o investimento psicológico das pessoas nessa questão ${ }^{25}$.

\section{RES U LTA D OS}

Das onze docentes entrevistadas, três eram doutoras, uma doutoranda, seis concluíram o mestrado e uma era mestranda, portanto, todas realizaram estudos de Pós-Graduação stricto sensu. Dois doutorados foram em saúde pública, um deles realizado na linha de pesquisa de educação em saúde. Os mestrados que os precederam também foram realizados nas mesmas áreas, portanto apenas um em educação em saúde. Das nove docentes restantes, uma tinha mestrado em educação, e as demais em áreas diversas. Em suma, das onze entrevistadas apenas duas tinham formação específica para a área em que atuavam.

Observou-se grande variação nas condições em que se desenvolve a prática de educação nutricional, e que não há consenso sobre o significado atribuído à atividade prática. Portanto, faz-se necessária a apresentação dessas significações para que a relação teoria-prática possa ser discutida posteriormente. Os vários tipos de atividades relatadas foram agrupados em um quadro-resumo (Quadro 1).

Algumas docentes consideram como atividade prática a elaboração de materiais de apoio como folders, por exemplo, ou outras atividades desenvolvidas no âmbito da própria faculdade, quando se faz simulação de atividade prática e os próprios colegas de turma participam representando a comunidade.

A carga horária da disciplina se apresenta como um obstáculo para a relação teoria-prática. Uma professora expôs o problema de esta ser tão reduzida em sua Universidade, com apenas 12 horas teóricas, o que inviabiliza o contato dos 
Quadro 1. Significados atribuídos à palavra prática pelas docentes da disciplina educação nutricional. São Paulo, SP, 2006.

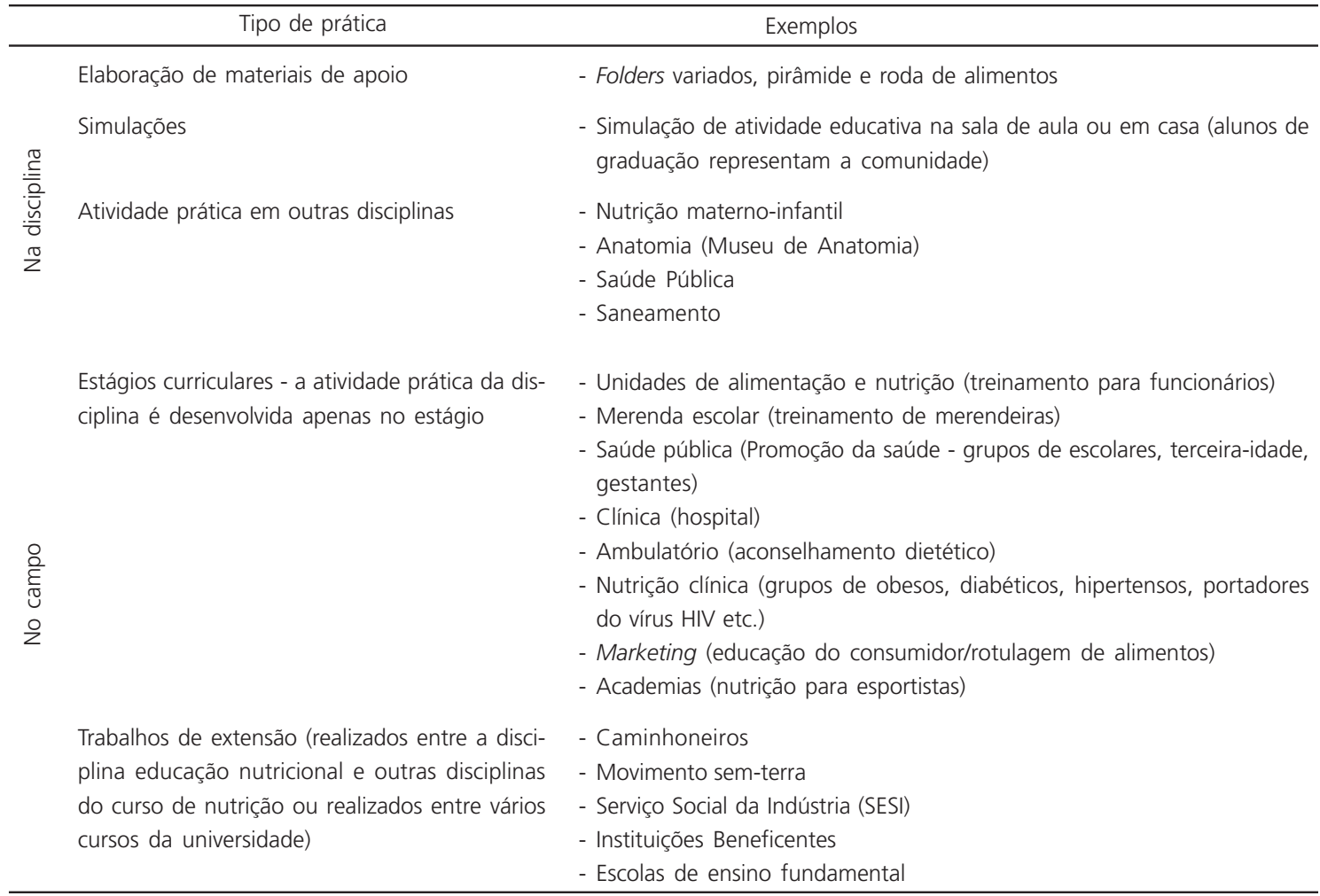

alunos com a prática. No final do ano letivo, eles elaboram e apresentam um trabalho prático, realizado na comunidade, e o apresentam em forma de filme para avaliação final da disciplina, já que a professora não tem disponibilidade para realizar supervisão direta.

[...] a carga teórica é um pouco reduzida por a gente ter que dividir essa disciplina em duas. Então, como avaliação nutricional tem uma carga muito pesada a gente tem duas horas semanais para educação nutricional durante seis semanas, então, na realidade, são 12 horas apenas, isso de carga teórica. Carga prática, durante as aulas esses alunos são estimulados, então, em casa, eles preparam folders, preparam algumas simulações de programas de educação nutricional, mas isso são apenas duas vezes dentro da disciplina [...] (Cânfora).

Algumas docentes relataram que há uma prática de educação nutricional realizada em outras disciplinas como nutrição materno-infantil, saúde pública e anatomia. Nesta última disciplina, há uma atividade educativa, na qual os alunos do terceiro ano de nutrição colaboram com os alunos do primeiro ano para o desenvolvimento de uma ação educativa em um Museu de Anatomia, junto aos freqüentadores desse local, visando ao reconhecimento do aspecto anátomo-fisiológico da digestão e alimentação.

Quanto aos estágios como possibilitadores da efetivação da relação entre teoria e prática, para uma das docentes a prática fica restrita a esse momento. Ela expôs a dificuldade de prática durante a disciplina, que é ministrada no período noturno. Outra professora teceu críticas à falta de comprometimento do curso em estimular a educação nutricional em outros campos de estágio, além de saúde pública. O Quadro 1 evidencia que as atividades práticas se concentram nos estágios. Além das áreas mais tradicionais, surgem outras novas, como educação do consumidor durante o estágio de marketing, realizada em supermer- 
650 A.C. FRANCO \& M.C.F. BOOG

cados, com o intuito de ensinar os compradores a entender as informações contidas nos rótulos de alimentos e, até mesmo, explicar a ordem em que os alimentos devem ir para o carrinho (não perecíveis, perecíveis, resfriados, congelados).

O estágio realizado, via de regra, no final do curso, deveria, em tese, instigar a interdisciplinaridade, aqui compreendida como relação existente entre disciplinas do mesmo curso. As duas falas seguintes evidenciam diferentes pensamentos quanto a essa integração de conhecimentos da disciplina durante o estágio de saúde pública:

[...] a gente tenta também discutir esse assunto em saúde pública, né, administração em saúde pública, enfim, mas essa abordagem é um pouco mais reduzida por falta de tempo realmente [...] (Cânfora).

[...] Saúde Pública é onde mais é cobrado educação nutricional. Onde o trabalho é permeado mesmo pela disciplina [...] (Lavanda).

Das onze entrevistas, apenas em uma foi feita referência à falta de tempo para que houvesse uma prática de educação nutricional no estágio de saúde pública. Em todas as outras, essa área foi citada como campo privilegiado de atuação do graduando enquanto educador.

Normalmente a disciplina educação nutricional torna-se mais presente nas áreas de estágio nas quais o próprio professor exerce a função de supervisor ou naquelas em que o professor supervisor, de qualquer uma das áreas de estágio, atribui grande importância à disciplina.

[...] a gente tem uma área que é nutrição social, que seria saúde pública como um todo [...] em UAN ou em clínica eu não percebo [...] que isso seja cobrado do aluno, não. Veja, isso é o que eu vejo acontecer, mas isso não é minha leitura, eu acho que deveria existir um vínculo maior (Camomila).

Das 10 instituições estudadas, seis desenvolvem projetos de extensão envolvendo a disciplina educação nutricional, sendo que, desses, dois são realizados interdisciplinarmente, com outros cursos da universidade, e os outros quatro são apenas do curso de nutrição, podendo incluir mais de uma disciplina. Os Projetos de Extensão foram citados como veículo possibilitador da prática em educação nutricional, que, neste caso, está sendo entendida como a atuação dos alunos junto à comunidade: caminhoneiros, Movimento Sem-Terra, Serviço Social da Indústria (SESI), Instituições Beneficentes e escolas de ensino fundamental da rede pública.

De forma geral, as docentes consideraram as atividades práticas muito importantes na disciplina educação nutricional e explicaram que, embora essa disciplina contenha essencialmente carga horária teórica, elas procuram desenvolvê-la incluindo prática:

[...] Você não pode ficar só em questão de teoria [...], Paulo Freire ou do Piaget, você tem que passar isso sim, mas você também tem que colocar ele na realidade, porque isso vai facilitar muito mais o processo ensino-aprendizado [...] (Bálsamo).

[...] eu consigo ver um grande amadurecimento no momento que eles visualizam a prática, quando eles põem a mão na massa, né? [...] quando a gente faz é que realmente entende (Almíscar).

[...] eu ainda colocaria uma importância maior para o lado prático. Porque o aluno vem com toda uma carga teórica [...], um conteúdo cientifico da área da nutrição. Então, essa parte prática é fundamental para ele exercitar, como eu vou me fazer entender, como eu vou transmitir aquilo que eu quero, como eu vou estimular a mudança de comportamento. Não basta passar uma informação, tenho que passar uma habilidade e para isso já vai entrar o lado prático (Mirra).

[...] eu trabalho sempre a parte teórica junto com a prática, então eu vou aliando as duas. [...] Porque se a disciplina fica muito teórica eles ficam muito ansiosos (Alfazema). 
A importância da prática é percebida pela totalidade das docentes, entretanto nem todas elas conseguiram explicitar com clareza o porquê de inserir, ao longo da graduação, atividades práticas. A fala que segue destacou-se das demais, porque a professora demonstra que, para ela, a prática não é apenas o momento de aplicar a teoria, mas a oportunidade que o aluno tem para refletir, elaborar idéias, de forma que o seu construto teórico não seja resultante apenas de uma assimilação de conteúdos seguida de treinamento prático (estágio), mas fruto de ação-reflexão-ação.

[...] Eu acredito que para que o profissional tenha uma postura diferente enquanto educador, no seu campo de trabalho, ele deve ter a possibilidade de presenciá-la na graduação. Então, as primeiras estratégias são no sentido de oferecer oportunidades de viver uma ação de ensino-aprendizagem diferente. [...] ao mesmo tempo que a gente vai desenvolvendo leituras, discussões, embasamento teórico, sempre de forma participativa, o aluno começa a diagnosticar, desenvolver na prática, planejar ações educativas para grupos reais [...] (Âmbar).

\section{I S C U S S Ã O}

Apesar do aparecimento de temas recorrentes que nos remetem a Paulo Freire, assim como das mensagens "ir a campo", "visão crítica dos alunos", "colocar na realidade", "prática e reflexão dos alunos", "trabalho é permeado", "quando a gente faz é que realmente entende", "viver uma ação", "grupos reais", pôde-se perceber a restrita discussão acerca do núcleo central das idéias freireanas, que é possibilitar a reflexão crítica sobre a realidade a fim de desvendar as armadilhas ideológicas e promover a autonomia e a emancipação dos educandos.

O papel do educador, nessas condições, seria o de estimular reflexões sobre as condições concretas de existência, analisar as situações vividas, identificar os obstáculos que limitam o acesso à qualidade de vida e ao pleno exercício dos direitos de cidadão, para encontrar, individual e coletivamente, caminhos para superar essas condições. Isso não significa impor certa visão de mundo, mas dialogar com o educando de forma que o processo ensino-aprendizagem aconteça a partir do conhecimento crítico da realidade ${ }^{13}$.

Uma possível explicação para a falta de consenso sobre o ensino e a prática de educação nutricional, nos depoimentos, seria a falta de uma teoria capaz de contemplar os complexos aspectos desse tema, fazendo com que haja uma busca pelas teorias das ciências sociais, assim como concluído por Achterberg \& Miller26, ao realizarem um estudo sobre as teorias existentes em educação nutricional. Essas autoras encorajam o desenvolvimento e a exploração de teorias e a geração de novas idéias, considerando que algumas são melhores do que outras. Entretanto, afirmam que nenhuma é boa o suficiente e concluem que o futuro é promissor, esperando que seja construída uma abordagem teórica mais compreensiva e efetiva para a educação nutricional.

Em uma das falas, foi citada a ansiedade vivenciada pelo aluno no momento em que a teoria é discutida na disciplina. Esse fato pode ocorrer devido a dois motivos: um é a pouca familiaridade com conteúdos afins às ciências humanas e o outro é a inquietude em relação à prática. $O$ aluno sente dificuldade ao se deparar com algo novo e, nessas condições, poderá demonstrar medo e apreensão, porém o enfrentamento dessas manifestações favorece a experiência, essencial para o futuro profissional ${ }^{27}$.

Não se pode esquecer a questão da supervalorização da teoria em detrimento da prática, presente em grande parte dos cursos universitários, queixa freqüente de alunos, que revela a inadequada utilização do tempo no decorrer da disciplina e a falta de reflexão sobre os conceitos teóricos no momento da prática ${ }^{20}$. Esse fato pode ser evidenciado ao comparar as instituições que oferecem carga horária prática da disciplina educação nutricional e o fazem numa relação que vai de 20 a $50 \%$ do total de horas ${ }^{28}$, o que não 
652 A.C. FRANCO \& M.C.F. BOOG

impede a oferta de uma prática posterior nos estágios, assim como foi mencionado pela maioria das docentes entrevistadas.

Os resultados evidenciaram que, para alguns professores, a atividade prática, quando presente na disciplina, é entendida como elaboração de instrumentos de apoio, sendo realizada de forma pontual, em sala de aula, e não relacionada a outras atividades, ficando a prática de campo restrita aos estágios que ocorrem em momento posterior. Alguns autores criticam esta separação entre teoria e prática, quando a prática é considerada apenas uma aplicação da teoria, de forma descontextualizada ${ }^{13,15,20}$.

As simulações também foram citadas como "situações práticas", embora, nessas condições, os alunos não entrem em contato com os atores sociais e com as dificuldades encontradas no campo de trabalho. Nessa perspectiva, pode-se sugerir uma visão ingênua da realidade, pois a simulação não permite estimular a consciência reflexiva do educando que, privado de exercitar a compreensão da realidade, não poderá desafiá-la a fim de buscar soluções ${ }^{13}$.

A realidade da vida e das situações a serem enfrentadas na profissão não pode ser simplificada e reduzida a questões que se resolvem dentro de uma ou outra disciplina. O enfrentamento da complexidade exige pensar "a sinergia, a orquestração de recursos cognitivos e afetivos diversos para enfrentar um conjunto de situações" 29 . Para Perrenoud ${ }^{29}$, o aluno experimenta uma tensão para o seu aprendizado: o desejo de compreender o professor, simultâneo ao desejo de construir suas próprias respostas. Essa tensão pode ser resolvida na prática, quando ele tem a oportunidade de agir na concretude da vida e isso só se efetiva se o aluno construir suas próprias respostas aos desafios, desenvolvendo a competência para resolver problemas complexos, navegando entre valores contraditórios e enfrentando toda rede de conflitos.

A maioria das docentes afirmou considerar o estágio o momento ideal para a efetivação da relação teoria-prática e o campo citado como o mais favorável ao exercício dessa relação foi o da saúde pública. A idéia tão interiorizada entre os profissionais de nutrição, de que esse é o campo próprio da educação nutricional, nem sempre se sustenta no confronto com a realidade. Isso foi demonstrado em estudo realizado na região metropolitana de Campinas, SP, no qual, dos 19 municípios que a compõem, apenas 8 contam com nutricionista; a relação nutricionista/população, varia de 1:20.000 a 1:1.000.000 de habitantes e as atividades desenvolvidas são, primordialmente, assistenciais, envolvendo educação, porém não na perspectiva da promoção da saúde ${ }^{30}$.

Portanto, as intervenções em saúde pública, poderiam ser complementadas com reflexões que possibilitassem um conhecimento crítico dos obstáculos sociais, políticos, culturais e ideológicos que impedem o pleno exercício profissional do nutricionista e a sua efetiva inserção na Rede Básica de Saúde.

A atuação em educação nutricional parece ser considerada inerente à área social pelos nutricionistas, entretanto, o campo pedagógico merece maior aprofundamento em todas as disciplinas do curso de nutrição, pois uma única disciplina não seria suficiente para provocar mudança de atitude $^{31}$

Amorim et al. ${ }^{7}$ expõem que, na maioria das vezes, as atividades de estágio acontecem no último ano da graduação e, considerando que esse é o primeiro e único momento de aproximação da teoria com a prática, há dificuldade da realização de redirecionamentos dos conteúdos trabalhados desde o primeiro ano do curso para a aplicação no campo de trabalho. Essa é uma questão central a ser debatida nos projetos pedagógicos, pois, conforme o recomendado pelas DCNCN, há necessidade de integração com a prática desde o primeiro ano da graduação'. Fagundes \& Burnham ${ }^{11}$ analisam as relações entre espaço e aprendizagem, constatando que:

[...] os atuais currículos, ao trabalharem com um modelo de organização que pressupõe a precedência da aprendizagem de referenciais teóricos para depois "aplicá-los" na realidade, reduzem os 
"espaços da prática" a meros "receptores" de conteúdos fragmentados, estudados em sala de aula. Nesta concepção de organização curricular, os "campos de prática" são percebidos como instâncias que pouco têm a oferecer em termos de articulação de novas aprendizagens e da socialização/produção de novos conhecimentos. É preciso, pois, compreender as circunstâncias nas quais as aprendizagens ocorrem, para que se possa pensar em modificações ou inovações curriculares a partir da estreita relação teoria-prática ${ }^{11}$ (p.106).

Essa é a fragmentação de conteúdos combatida por Morin, que informa que o conhecimento pertinente é aquele que contém a totalidade da informação, que consegue distinguir a multidimensionalidade dos fatos e acontecimentos, a fim de promover a "inteligência geral" capaz de se referir ao complexo e ao contexto.

Os locais dessas práticas curriculares deveriam ser entendidos como meios inspiradores de reflexão e produção de conhecimento. No entanto, não se pode esquecer as hierarquias e a conseqüente postura autoritária de alguns profissionais nos campos tradicionais da formação nas áreas de saúde, cabendo, portanto, à universidade, a busca de campos mais favoráveis ao compartilhamento dos saberes e práticas ${ }^{13}$.

Outro enfoque sobre a prática refere-se ao trabalho com grupos e ao atendimento ambulatorial que acontecem, principalmente, durante os estágios de nutrição clínica e saúde pública. Rodrigues et al. ${ }^{32}$ chamaram a atenção para o fato de que a graduação em nutrição, normalmente, não prepara o aluno para o trabalho com grupos. Diante dessa observação e dos resultados obtidos, cabe apontar a importância de preparar o aluno para esse trabalho, em que existe a intenção de compartilhar e dividir problemas, conhecimentos e experiências dos participantes, cabendo ao nutricionista o papel de facilitador, a fim de criar uma atmosfera confortável para as discussões, encorajar a participação e interferir apenas para corrigir as informações incorretas. As discussões são baseadas no aprendizado participativo no qual há colaboração e o engajamento dos participantes na re-elaboração das questões discutidas, o que os ajuda na modificação de atitudes e comportamentos ${ }^{33}$. Para uma atuação significativa no grupo, o profissional necessita dominar conhecimentos sobre a dinâmica do campo grupal, conhecer a natureza dos vínculos que se estabelecem entre as pessoas, os papéis que elas desempenham no grupo, enfim, a dinâmica interacional do grupo ${ }^{34}$, temas que deveriam integrar o conteúdo teórico da disciplina.

$O$ atendimento ambulatorial, por sua vez, remete a um conhecimento teórico sobre aconseIhamento dietético. No Brasil, utiliza-se pouco essa terminologia que é, até mesmo, desconhecida, apesar de ter sido empregada por uma autora brasileira, pela primeira vez, em $1976^{32}$. Em apenas uma fala observou-se tal nomeação para a consulta de nutrição.

A prática realizada dentro dos projetos de extensão, no momento em que o aluno entra em contato com a comunidade, possibilita a construção de conhecimento crítico quando ele é estimulado a realizar o movimento dialético do abstrato ao concreto ${ }^{14}$. Essa articulação de saberes se estabelece em uma aliança com a comunidade, tendo como base a perspectiva de elaboração de novos projetos em comum, sendo necessário o estabelecimento de parcerias e cooperações para que, então, haja o devido acolhimento dos professores e alunos ${ }^{21}$. Imbernón ${ }^{18}$ aponta a importância da interação entre programas de ensino e comunidade, ao discorrer sobre a necessidade de mudança na formação dos professores, que deve abandonar o enfoque da racionalidade técnica e admitir um papel mais ativo em todas as fases de desenvolvimento e aplicação de programas de intervenção educacional, conjuntamente com a comunidade. Helitzer \& Wallerstein ${ }^{35}$ afirmam que a instrução acadêmica que ignora experiências práticas ou separa a teoria da prática, forma profissionais de saúde que têm, freqüentemente, dificuldade de trabalhar dentro dos contextos comunitários.

A constatação de diversos significados atribuídos à palavra prática pelas docentes, faz 
654 A.C. FRANCO \& M.C.F. BOOG

pensar nas implicações desse fato na formação profissional e na própria possibilidade de efetivação da relação teoria-prática. A prática em educação nutricional acontece, de fato, quando o aluno entra na realidade estudada, a fim de intervir e refletir sobre ela, quando supera o pensamento ingênuo, ao assumir um compromisso com mudanças $^{13}$. Ele reconstrói a teoria estudada ao estabelecer uma relação dialética entre teoria e contexto social.

\section{O N CLUS Ã O}

As docentes apresentaram pensamentos similares em relação à importância da prática, considerando-a essencial e inerente ao exercício da profissão, porém divergiram em relação à concepção dessa prática. A importância atribuída pelos sujeitos à interlocução entre teoria e prática foi evidenciada em grande parte das falas, confirmando a percepção da necessidade desta articulação para a efetivação do processo ensino aprendizagem. No entanto, as diversas interpretações acerca da palavra prática e de como ela se realiza podem comprometer de forma significativa a construção de uma base teórica sólida que alicerce a formação do nutricionista. Não havendo consenso sobre o significado dessa prática, algumas docentes podem ter uma falsa concepção de que ela está realmente acontecendo.

Outro problema identificado é o da crença na supremacia da prática sobre a teoria, apontada por algumas docentes. Talvez, por não haver uma teoria específica de educação nutricional e ser necessária a busca de teorias das ciências humanas e sociais, haja um entendimento de que as atividades práticas são suficientes para a formação dos alunos.

A relação teórico-prática é importante desde o primeiro ano da graduação independentemente da disciplina, para que o aluno consiga estabelecê-la em todas as suas ações ao longo do curso. Não cabe somente à disciplina educação nutricional e aos seus docentes o papel do despertar da educação enquanto essencialidade da prática profissional, não podendo ser consi- derada como responsabilidade somente dessa disciplina. A docência nessa disciplina requer do professor uma formação específica, que transcende a área de nutrição e precisa ser obtida na área de ciências humanas ou em áreas que têm interfaces com as ciências humanas. No entanto, os demais docentes devem estar cientes do papel de educador que o nutricionista exercerá, em qualquer área de atuação.

Recomenda-se que seja estimulado, desde o início da formação, o desenvolvimento de responsabilidades e reconhecimento da importância das disciplinas de cunho social e educativo, como um dos aspectos inerentes à prática profissional. E, que cabe aos cursos de graduação, de Pós-graduação e aos Órgãos fiscalizadores do ensino, a discussão sobre como a prática pode e deve ser entendida, e em qual forma se mostra mais eficaz para fazer o movimento dialético com a teoria.

As reflexões aqui propostas têm a preocupação, não só, de contribuir para o aprimoramento do ensino, mas também para que a formação dos novos profissionais possibilite oferecer contribuições no plano social e político, no qual o nutricionista poderia exercer plenamente o seu papel, em todas as áreas, inclusive, na de educação nutricional, tendo por fim melhorar as condições de alimentação do País, promovendo a saúde e a qualidade de vida.

\section{REFERÊ NCIAS}

1. Brasil. Conselho Nacional de Educação. Câmara de Educação Superior. Resolução n.5 de 07.11.01. Institui Diretrizes Curriculares Nacionais do Curso de Graduação em Nutrição. Brasília; 2001.

2. Brasil. Conselho Nacional de Educação. Câmara de Educação Superior. Parecer 239/2004: carga horária mínima dos cursos de graduação, bacharelados, na modalidade presencial. Brasília; 2004.

3. Canesqui AM, Garcia RWD. Ciências sociais e humanas nos cursos de nutrição. In: Canesqui AM, Garcia RWD, organizadores. Antropologia e nutrição: um diálogo possível. Rio de Janeiro: Fiocruz; 2005. p.255-74.

4. Organización Pan-Americana de la Salud, Organización Mundial de la Salud. Formación academica de nutricionistas-dietistas en America 
Latina: guía para el desarrollo de planes de estudio y programas de enseñanza. Washington (DC): OPAS; 1977.

5. Brasil. Ministério da Saúde. Secretaria de Atenção à Saúde. Departamento de Atenção Básica. Política Nacional de Alimentação e Nutrição. 2a. ed. Brasília: Ministério da Saúde; 2005.

6. Morin E. Os sete saberes necessários à educação do futuro. 6a. ed. São Paulo: Cortez; 2002.

7. Amorin STSP, Moreira H, Carraro TE. A formação de pediatras e nutricionistas: a dimensão humana. Rev Nutr. 2001; 14(2):111-18.

8. Achterberg C. A perspective on nutrition education research and practice. J Nutr Educ. 1988; 20(5): 240-3.

9. Souza NA. A relação teoria-prática na formação do educador. Semina: Ci Soc Hum. 2001; 22:5-12.

10. Dinucci AC, Fernandéz ER, Ibarra MLG, Abalo RG. Representação social dos egressos da nutrição na Universidade Federal de Mato Grosso acerca do curso de graduação e da profissão de nutricionista. Psicol Educ. 2002; 14/15:165-88.

11. Fagundes NC, Fróes Burnham T. Discutindo a relação entre espaço e aprendizagem na formação de profissionais de saúde. Interface: Comunic, Saúde, Educ. 2004; 9(16):105-14.

12. Miranda $\mathrm{KCL}$, Barroso MGT. A contribuição de Paulo Freire à prática e educação crítica em enfermagem. Rev Latino-Am Enfermagem. 2004; 12(4):631-5.

13. Freire P. Educação e mudança. 10a. ed. Rio de Janeiro: Paz e Terra; 1985.

14. Freire P. Pedagogia da autonomia: saberes necessários à prática educativa. 28a. ed. São Paulo: Paz e Terra; 2003. Coleção Leitura.

15. Freire P. Pedagogia do oprimido. 38a. ed. Rio de Janeiro: Paz e Terra; 2004.

16. Pereira ALF. As tendências pedagógicas e a prática educativa nas ciências da saúde. Cad Saúde Pública. 2003; 19(5):1527-34.

17. Cyrino EG, Toralles-Pereira ML. Trabalhando com estratégias de ensino-aprendizado por descoberta na área da saúde: a problematização e a aprendizagem baseada em problemas. Cad Saúde Pública. 2004; 20(3):780-8.

18. Imbernón F. Formação docente e profissional: formar-se para a mudança e a incerteza. 5a. ed. São Paulo: Cortez; 2005. Coleção Questões da nossa época, v.77.

19. Mogilka, M. Educar para a democracia. Cad Pesquisa. 2003; 119:129-46.

20. Timoteo RPS, Liberalino FN. Reflexões acerca do fazer pedagógico a partir de referências e diretrizes educacionais para a formação em enfermagem. Rev Bras Enferm. 2003; 56(4):358-60.
21. Turato ER. Métodos qualitativos e quantitativos na área da saúde: definições, diferenças e seus objetos de pesquisa. Rev Saúde Pública. 2005; 39(3):507-14.

22. Minayo MCS. O desafio do conhecimento: pesquisa qualitativa em saúde. 7a. ed. São Paulo: Hucitec; 2000.

23. Achterberg C. Qualitative methods in nutrition education: evaluation research. J Nutr Educ. 1988; 20(5):244-50.

24. Gil AC. Métodos e técnicas de pesquisa social. São Paulo: Atlas; 1999.

25. Bardin L. Análise de conteúdo. 3a. ed. Lisboa: Edições 70; 2003.

26. Achterberg C, Miller $C$. Is one theory better than another in nutrition education? A viewpoint: more is better. J Nutr Educ Behav. 2004; 36(1):40-2.

27. Scherer, ZAP. Grupoterapia e Enfermagem: o estudante e a transição teórico-prática [tese]. Ribeirão Preto: Universidade Estadual de São Paulo; 2005.

28. Franco AC. Educação nutricional na formação do nutricionista: bases teóricas e relação teoria-prática [dissertação]. Campinas: Universidade Estadual de Campinas; 2006.

29. Perrenoud P. Ensinar: agir na urgência, decidir na incerteza. 2a. ed. Porto Alegre: Artmed; 2001.

30. Pádua JG. Avaliação da inserção do nutricionista na rede básica de saúde dos municípios da região metropolitana de Campinas [dissertação]. Campinas: Universidade Estadual de Campinas; 2004.

31. Ramos SPS. A educação nutricional sob o olhar dos docentes do curso de nutrição [dissertação]. Campinas: Pontifícia Universidade Católica de Campinas; 2004.

32. Rodrigues EM, Soares FPTP, Boog MCF. Resgate do conceito de aconselhamento no contexto do atendimento nutricional. Rev Nutr. 2005; 18(1): 119-28.

33. Abusabha R, Peacock J, Achterberg C. How to make nutrition education more meaningful through facilitated group discussions. J Am Diet Assoc. 1999; 99(1):72-6.

34.Zimermam DE. Fundamentos básicos das grupoterapias. 2a. ed. Porto Alegre: Artes Médicas Sul; 2000.

35. Helitzer D, Wallerstein N. A proposal for a graduate curriculum integrating theory and practice in public health. Health Educ Res. 1999; 14(5):697-706.

Recebido em: 12/8/2006

Versão final reapresentada em: 19/9/2007

Aprovado em: 10/10/2007 